CASE TENDING TO PROVE THE UNEQUIVOCAI EFFICIENCY OF TIY

\section{SECALE CORNUTUM}

IN MENORRHAGIA RUBRA.

\section{With adventitious Remarks on}

OBSTINATE ADIESION OF THE PLACENTA, AND ON FEEAL EVOLUTION.

By Richand Lavion, Jun., Esq., F.A.S., \&ic., Lostwithiel.

Ir was not my intention to have obtruded on Tue Lancer any furtber remarks on the ergot of rye, conceiving its use to be too firmly established in practice to require further commendation; but the discussion to which it some time since gave rise in the Westminster Medical Society, together with the contradictory statements which that discussion elicited, will, 1 hope, be deemed a sufficient apology for my wishing to place on record the following case :-

Ahout eight months since a woman of good constitution, the mother of several children, at. 40 , was the subject of obstinate sanguineous uterine discharge, which was suffered to proceed uninterruptedly for nearly two months. Eventually she became alarmed, and sought relief, which the usual treatment refused to afford.

At this period I saw her, and was informed that the discharge had intermitted occasionally for a few days,- - that it had ever been small in quantity, and that she was more alarmed by its continuance than by its severity. She had been taking the dilute sulphuric acid, which was recommended to be continued in increased doses ; and as her spirits were good, with a pulse indicative of considerable constitutional energy, and, more especially, as she was not a little inclined to the en bon point, it was thought advisable to institute a decisive general bleeding. The horizontal position was strictly enjoined, and cold epithems to the pudenda perseveringly used. After continuing this treatment several days ineffectually, it was determined still to persevere with precisely the same remedies independently of the bleeding, and thinking this an excellent opportunity to prove the efficiency or non-efficiency of the secale cornutum, its infusion was made a rehicle for the administration of the acil. Two scruples of the ergot in rough powder being infused for two hours in four ounces of boiling water, a quarter part was directed to be taken every tre hours, which in two days arrested the discharge. She regularly continued her medicine for three weeks without a relapse.

Few persons hare had more frequent opportunities of using the ergot very ex- tensively than myself, and from that experience I have been led to the conclusion that it exerts no particular influence in obliging the uterus to retain the placenta obstinately after expulsion of the foetus. I have had frequent opportunities of introducing my hand into the uterus, both be.. fore and after fotal delivery, but the impe. diments now have not been more numerous than before the ergot was generally intro. dueed.

My practice furnished me some short time since with rather an extraordinary case. A woman who, on her previous accouchements, had been disposed to fearful hæmorrhagic discharges, took a full dose of the ergot immediately on my entering her room. This was her fifth labour, the membranes had been ruptured before my arrival, the os uteri was dilated to about the size of a crown-piece, and was not rigid, with a vertex presentation. The parturient efforts had subsided sometime be. fore I arrived, and having waited nearly two hours after the ergot had been exhibited before they returned, I then examined, and to my astonishment found the vertex presentation replaced by the arm protruding into the yagina. Delivery, however, was very easily effected by the feet. Whetler this evolution was induced by the secale cornutum or was spontaneous, is a point which can only be determined by future $e x$ perience.

Oct. 1831.

\section{CASE OF}

\section{FRACTURE OF THE OS PUBIS,}

\author{
WITH SEVFRE INJURY OF THE \\ BLADDER AND RECTUM.
}

By Robert Merry, Esq., M.R.C.S, and late House-Surgeon to the IVest Herts Infirmary.

Georcie Bedford, retat. 42 , was admitted a patient of the West Ilerts Infirmary on the $3 \mathrm{~d}$ of June, 1830.

Four p.m. I understood from the persons who brought him, that whilst adjusting a stone behind the wheel of a lieavily-laden timber carriage, he slipped down, and ere he could regain his feet, the hind wheel backed over him, and the fore-wheel rested for some seconds on his hip. Complains of severe pain of the right hip, pubic, and right renal region; great pain also at the lower part of the abdomen, augmented by the siightest pressure, with inability to move the lower extremities; about an ounce of grumous blood passed per urethram; pulse 100, full; has no power to void his urine. Upon minutely examining the 
bones of the pelvis, I detected a fracture about half an inch from the symphysis on the right side. Applicentur hirudines xxiv regioni hupogastrici dextro, et detrahantur slatim venit brachali uncias duodecim sanguinis.

lo Iydrar. sabm. gr, v;

Pulv. antim., gr. iij ;

P'ulr. opii, gr. iss ;

Conf. rosit, q. s. ut ft. pil. ij. h. s. s.

Bo Haust. senna co., $\overline{\tilde{J}}$ iss, cras mane primo sumend.

I introduced the catheter, and drew off about a pint of urine, mixed with a large proportion of blood.

June + , six a.r. Has had no sleep, but is continually moaning; much pain in the refrion of the blalder. 1 repented the introduction of the catheter, and drew of half a pint of bloody urine, which reliered him. Twelve A.r. Less pain in the loins; the bowels have bren freely opened; complains of much pain in the perinaum, which is inflamed; pulse 1\%0; tongue furred; skin hot and dry; rreat anxiety depicted on the countenance. "Introduced an elastic catheter with the intention of letting it remain in the bladder, but it caused so much irritation that I was compelled to remove it. Ordered him-

\section{Ix Liq. ammon. acet., 冬iss; \\ Magnes. sulph., 5iij ;}

Liq. antim. tart., tinct. hyosciam, a a, Jैiss ;

Ayuce menth. sat., 3 iv. Mr. capt. I 1 em parten 4ta quaque horà.

Repeated the operation in the evening, when about a pint of urine passed, mixed with a considerable portion of dark blood.

5. Has had but an indifferent night; attempted to evacuate the bladder two or three times, but without any success. Hardness of the abdomen when touched, cries out with pain ; complains of pain about the neck of the bladder ind perinaum. Pulse 110, softer; slin moist; bowels kept open by the medicine. Introduced the catheter three times this dar, jemoving at each operation about half a pint of urine. Repetan. tur medicamenta.

o. Passed a better night ; tongue clean; pulse 100 ; less pain. Persistat in usu medicament. ut heri. The catheter introduced three times.

8. The pain chiefly confined to the perinaum, which appears to be suppurating; has no porrer of passing urine but $b y$ means of the catheter; pulse small and quick; bowels open. liepetantur medicamenta.

11. Less pain; pulse small ; tongue dry. Has bad shicering for the last two days; there is evidently matter formed in the perinzum.
12. Passed a restless night; perinæum more swollen and painful; plunged the lancet into it, and let out about ten ounces of fetid pus.

14. Complains of violent pain in the head; talking at times incoherently; also much pain in the abdomen, hard and swol. len; pulse 120, strong; skin dry; fetid pus and urine draining through the wound. Fiat renesectio ad $\mathfrak{3} \times \mathrm{rj}$.

$\mathrm{ll} O$ ol. ricini, 芌ss, statim.

Eight P.x. Relieved by the bleeding; bow ts freely opened. The urine has passed to-day parily with the stools and partly per perinæum; pulse 110 .

Bo Iiq. ammon. acet., 号iss;

Infus. senne, $\frac{5}{3} \mathrm{ijss}$;

Liq. antim. tart.,, $\mathrm{j}$;

Aquce cinnam., $\breve{3}$ ij. M. capt. cochl. tria magna 4ta quaque horà.

15. Much better. Repetantur medicamenta.

17. Complains of faintness; pulse small; tongue clean; urine passes per perinaum and rectum. The cntheter has been repeatedly introduced, but the bladder his always been found empty.

R Decoct. cinchone, 柔vss;

Tinct. ejusdem, 5 iij ;

Acid. sulph. dil., in xl. M. capt. $\frac{x}{4}$ tem partem ter die.

July 2. Much improved; wound healthy; urine passing as betore. Rep. mist, tonic.; meat diet.

5. Allowed the catheter to remain in all night, which caused very trifling uneasiness; a small quantity of urine dribbled through it.

9. No urine came from the wound yesterday or to-day, but partly per catheter and partly per rectum; wound nearly healed; bealth much improved; tongue clean. Ordered him to continue the bark, and to take four ounces of port-wine daily.

13. The urine passes principally per catheter, but a small quantity still per rectum.

25. Wound quite healed; urine comes by the catheter only, healthy; greatly improved; on introducing the metallic catheter, there is not any obstruction to its entering the bladder, but on moving it laterally, it is as firmly fixed as if in a vice, and in withdrawing, it gives the sensation to the hand as if striking against a calculus, which Mr. key (who examined him) considered to be the lower margin of the tractured os pubis.

$G$. Bedford was discharged cured August $26 \mathrm{rh}, 1830$, and is now the beadle of Hemel Irempsted parish.

Millfield House, Highgate, Oct. 12th, 1831. 